NBER TECHNICAL WORKING PAPERS SERIES

\title{
FINANCIAL INTERMEDIATION AND MONETARY POLICIES IN THE WORLD ECONOMY
}

Vittorio Grilli

Nouriel Roubini

Technical Working Paper No. 104

NATIONAL BUREAU OF ECONOMIC RESEARCH

1050 Massachusetts Avenue

Cambridge, MA 02138

May 1991

\begin{abstract}
We would like to thank David Begg, Alberto Giovannini, Roberto Tamborini, Stephen Turnovsky, Philippe Weil, the participants to the 1990 NBER Summer Institute and in workshops at Boston College, Columbia University, Georgetown University, London Business School and the University of Rochester for their comments and suggestions. The usual disclaimer applies. This paper is part of NBER's research programs in International Studies and Financial Markets and Monetary Economics. Any opinions expressed are those of the authors and not those of the National Bureau of Economic Research.
\end{abstract}


NBER Technical Working Paper \#104

May 1991

FINANCIAL INTERMEDIATION AND

MONETARY POLICIES IN THE WORLD ECONOMY

\section{ABSTRACT}

In this paper we investigate the role of credit institutions in transmitting monetary shocks to the domestic economy and to the rest of the world output. In modeling the monetary and financial sector of the economy we distinguish between monetary injections via lump-sum transfers to individuals and those via increased credit to the commercial banking sector in the form of discount window operations. Appropriately, we distinguish between the discount rate of the central bank and the lending and borrowing interest rates of commercial banks, which, we assume, are also subject to reserves requirements. We find that a steady state increase in monetary injections via increases in domestic credit leads to an increase in domestic output. On the other hand, we find that an increase in the steady state level of monetary transfers reduces the level of output.

Vittorio Grilli

Department of Economics

Birkbeck College

7-15 Gresse Street

London, W1P 1PA

England

NBER and
Nouriel Roubini

Department of Economics

Yale University

28 Hillhouse Avenue

New Haven, CT 06520

U.S.A.

NBER 


\section{INTRODUCTION}

In this paper we investigate the role of credit institutions in transmitting monetary shocks to the domestic economy and to the rest of the world output. We follow the strategy introduced in Grilli and Roubini [1989, 1991] which extended to an open economy framework pioneering work by Lucas [1991] on the liquidity effect of open-market operations. The crucial result of that setup was the existence of "excess volatility" of the exchange rate with respect to the usual fundamentals like nominal prices, output and terms of trade. Monetary injections, however, did not have any effect on the level of real activity since output was assumed to be fixed.

In this paper, instead, we allow for output to be endogenously determined, and we analyze whether and through which channels monetary policy affects real activity. A closely related framework can be found in Fuerst [1989] which extends Lucas' analysis to account for nonneutrality of monetary injections in a closed economy. Our work, however, differs in several important ways from Fuerst's analysis. First, we add realism and complexity to the the financial intermediaries, by distinguishing between lending and borrowing interest rates and by introducing banks' required reserves. Second, we distinguish between monetary injections via lump-sum transfers to individuals and those via increased credit from the central bank to the commercial banking sector. Finally, we develop our analysis in an open economy framework. We find that, contrary to Fuerst, a steady state increase in monetary injections via increases in domestic credit leads to an increase in domestic output. On the other hand, we find that an increase in the steady state level of monetary transfers reduces the level of output.

The novelty and contribution of this area of research as well as 
of this paper is obviously not the discovery that changes in the rate of growth of money can affect the level of real activity both domestically and internationally. This is a well-known issue and is one of the main subjects of macroeconomics and international finance. However, most of the classic models are highly aggregate or quite remote from institutional reality 1 . In this paper, instead, we explicitly model financial intermediaries in the form of credit institutions, and we stress their role in transmitting changes in monetary policies to the production sector domestically and worldwide. One important lesson of this approach is that the effects of monetary policy depend crucially on the specific channel through which the policy is implemented.

Relative to previous work, this paper can be seen as a contribution to the literature on the relation between monetary policy (and inflation) and steady state output and capital accumulation (see Tobin [1965], Sidrauski [1967], Fischer [1979], Stockman [1981], Stockman and Svensson [1987], Aschauer and Greenwood [1983], Cooley and Hansen [1989]). It differs from Tobin [1965], Fischer [1979] and Sidrauski [1967] in that here inflation has a negative effect on the steady state capital stock while it has a positive effect in Tobin and Fischer and no effect in Sidrauski. While it shares with Stockman [1981], Stockman and Svensson [1987], Aschauer and Greenwood [1983] and Cooley and Hansen [1989] the result of the negative relation between monetary growth and the level of economic activity, it differs from these contributions in several respects. First, it considers in detail the role of financial intermediaries in transmitting monetary policy to the level of economic activity; second, it presents a two-country open economy analysis that allows to analyze the international spillover effects of monetary policies; third, by distinguishing between different sources of 
monetary injections, it shows that the positive or negative output effects of monetary policy depend crucially on the way money is injected in the economy.

An important analysis considering the role of financial intermediaries in the international transmission of economic disturbances is the one by Greenwood and Williamson [1989]. Our model differs from their in a number of respects. First, the theoretical framework and the channels of transmission of monetary policy are different in the two models. Second, compared to our analysis, where the existence of financial intermediaries is assumed exogenously, their model shows how financial intermediation will emerge endogenously as an incentive-compatible means of economizing on monitoring costs. Third, while our model implies the existence of perfect international capital mobility, in their model the existence of transaction costs lead to a partial segmentation of international capital markets and a limited degree of capital mobility.

In Section 2 we informally describe the structure of the economy underlying our analysis. In Section 3 we formally analyze an environment in which domestic labor is the only factor of production. In Section 4 we modify the model by assuming that domestic capital (intermediate goods) are needed for production. Section 5 extends the analysis by assuming that foreign working capital (intermediate goods) is also needed in the production. Section 6 concludes.

\section{THE BASIC STRUCTURE OF THE WORLD ECONOMY}

Before presenting in analytical detail the structure of the model it is useful to describe the agents in the economy, the various markets and the economic transactions taking place in these markets. 
To keep the analysis simple we make the assumption of perfect foresight throughout the paper. We are considering a two-country world economy; each country produces one consumption good while it consumes both domestic and foreign goods. The domestic good is produced with work (and capital in the versions of the model with capital investment). Domestic and foreign goods are traded in goods markets without trade restrictions; we also assume that there are no restrictions to international capital movements so that perfect international capital mobility is holding. As in Lucas [1991], Grilli and Roubini [1989] and Fuerst [1989] we assume the convenient artifact of a multi-member representative household: each member has a different task during a period and the household regroups at the end of the period to pool goods, assets and information. This assumption is quite convenient because it prevents monetary injections from creating wealth redistribution effects that persist in the future.

As in Fuerst [1989] (who considers a closed-economy model), the representative household is composed of a shopper, a firm manager, a worker and a financial intermediary: the shopper deposits part of the initial household's domestic and foreign monetary balances in the financial intermediary (the bank) and goes to the goods markets with the remaining monetary balances to buy domestic and foreign consumption goods. Once the division of the initial money balances in deposits and currency for goods is made no further portfolio reshuffling is allowed during the period; one could think of this assumption as deriving from transaction costs that do not allow the shopper to continuously adjust its monetary balances during the transaction period. The financial intermediary borrows funds from the household and lends funds to the domestic and foreign firms. For simplicity, we assume that 
banks accept deposits and make loans only in their national currency. The firm manager needs to borrow funds from the bank because it has to pay the wages and buy capital for production purposes. The wages received by the workers are available for consumption only in the following period. Finally, the good produced by the firm is sold in the good markets to the shopper.

Formally, money is introduced in the model by assuming cash-in-advance constraints such that all purchases and transactions require the use of monetary balances. As standard in this literature, we assume that domestic goods can be bought only with domestic currency and foreign goods only with foreign currency.

We consider two different types of monetary injection: first, the usual 'helicopter drop' increase in the money supply in the form of a nominal lump sum transfer from the government to the households; second, a monetary injection through the credit system, similar to a discount window operation. This second type of injection is assumed to be sterilized via a lump sum transfer to the household, and thus, does not affect the rate of growth of money. This allows us to compare the real effects of monetary injections that affect the rate of growth of money with those of injections that leave the money supply unchanged.

The commercial banks' liabilities are the sum of the household deposits and the monetary injection. These funds are lent to the firm who uses them to buy its factors of production. 2 The nominal interest rates (deposit and lending rates) are determined in the deposit and loan markets and must be such that all the funds of the banks are borrowed by the firms: this is the mechanism through which monetary injections to the banking system will affect interest rates. Given that we are assuming international capital mobility and integrated asset markets 
that include the foreign exchange rate market, these monetary shocks will also affect the exchange rate. An increase in the rate of growth of money leads to an increase in both borrowing and lending rates while a positive monetary injection through the credit system leads to a reduction in domestic borrowing rates only. These interest rate effects are the link between monetary policies and output. Anticipating our conclusions, monetary injections in the form of credit expansions increase output because they imply a subsidy to the production sector. In fact, it is equivalent to a transfer of seigniorage revenues from the monetary authorities to the firm. Conversely, increases in the rate of growth of money through monetary transfers to individuals reduce domestic output because they increase the level of the inflation tax which leads to a reduction of labor supply.

\section{MODEL WITH LABOR SUPPLY DECISIONS}

Consider a world economy consisting of two countries, 1 and 2 populated by identical infinitely-lived households with preferences given by

$$
U_{i}=\sum_{t=0}^{\infty} \beta^{t}\left[U\left(c_{i t}^{A}, c_{i t}^{B}\right)+Z\left(1-L_{i t}\right)\right] \quad i=1,2
$$

where $\beta=(1 /(1+\rho))$ and $\rho$ is the rate of time preference. The subscript $i$ refers to the nationality of the household, and the superscripts $A$ and $B$ to the nationality of goods and assets ( $A$ for the products of country 1 and $B$ for the products of country 2). Thus $c_{i t}^{A}$ indicates the consumption (at time $t$ ) by residents of country $i$ of goods produced by country 1 and $c_{i t}^{B}$ (at time $t$ ) the consumption by residents of country $i$ 
of goods produced by country 2. Similarly, $\mathrm{L}_{i t}$ is the amount of time spent working. (Total time available is normalized to one.) The production possibility (at time $t$ ) of this economy is summarized by:

$$
Y_{t}^{j}=\mathrm{f}^{j}\left(H^{j}\right)
$$$$
j=A, B
$$

where $Y^{A}$ and $Y^{B}$ are the output of goods produced by countries 1 and 2 respectively; $H^{A}$ and $H^{B}$ are the aggregate supply of labor in country 1 and country 2. Therefore, domestic labor is the only factor of production in this setup.

Because of the symmetry between the two economies we concentrate on the problem faced by the representative family of country 1, keeping in mind that an identical analysis would apply to the households of country 2. Given our assumption about the family and the market structure, in each period the household faces different cash-in-advance constraints. The "shopper" faces

$$
\begin{aligned}
& \mathrm{M}_{1 t}^{A}-N_{1 t}^{A} \geq P_{t}^{A}{ }^{c^{A}}{ }_{1 t}^{A} \\
& \mathrm{M}_{1 t}^{B}-N_{1 t}^{B} \geq P_{t}^{B}{ }_{t}^{B}{ }_{1 t}^{B}
\end{aligned}
$$

where $\mathrm{M}_{1 t}^{A}$ is the total amount of money of country 1 held by residents of country $1, N_{1 t}^{A}$ is the amount of country 1 money deposited in bank accounts. (Recall that we assumed that residents of country 1 can have deposits denominated in both $A$ and $B$, and that domestic (foreign) currency deposits are held only in domestic (foreign) banks.) Therefore, $\left(\mathrm{M}_{1 t}^{A}-N_{1 t}^{A}\right)$ and $\left(\mathrm{M}_{1 t}^{B}-N_{1 t}^{B}\right)$ are the total amounts of currency $A$ and currency $B$ available for transactions in the goods markets. $P^{A}$ is 
the nominal price in currency $A$ of good $A ; P^{B}$ is the nominal price in currency $B$ of good $B$.

The monetary injection in the economy takes two forms:

1) A nominal lump sum transfer from the government to the household $\left(V_{t}\right)$.

2) A monetary injection through the banking system that could be thought as an increase in credit from the central bank to the commercial banks $\left(\Delta_{t}\right)$.

We want to distinguish between monetary injections that lead to an increase in the money supply and monetary injections that represent a redistributive transfer between different economic sectors. Therefore we introduce a nominal lump transfer $\mathrm{S}_{\mathrm{t}}$ equal to ${ }^{C}{ }_{C B} \Delta_{\mathrm{t}}$, where ${ }^{i} C B$ is the discount rate paid by the commercial banks to the central bank. This transfer is assumed to be paid to the household. This implies that only monetary transfers $V_{t}$ lead to an increase in the money supply while expansions of credit to the banking system $\left(\Delta_{t}\right)$ are completely sterilized and have no effect on money supply. Summarizing, the evolution of the money supply is thus given by:

$$
M_{t+1}^{i}=M_{t}^{i}+V_{t}^{i}+\Delta_{t}^{i}-\left(1+{ }_{C B}\right) \Delta_{t}^{i}+S_{t}^{i}=M_{t}^{i}+V_{t}^{i} \quad(i=A, B)
$$

since we assumed that $S_{t}^{i}={ }^{i} C B^{\Delta}{ }_{t}^{i}$.

The "firm," on the other hand, faces:

$$
B_{1 t}^{A} \geq W_{t}^{A} H_{t}^{A}
$$

where $B_{t}^{A}$ is the total amount of loans taken by the firm; $W_{t}^{A}$ is the 
nominal wage rate, and thus $W_{t}^{A} H_{t}^{A}$ is the total amount of salaries to be paid out by the firm. In turn, the loans made by the banks to the firms $\left(B_{t}^{A}\right)$ are equal to:

$$
B_{t}^{A}=(1-R)\left[N_{t}^{A}+\Delta_{t}^{A}\right]
$$

where $R$ is the required reserve coefficient and $N_{t}^{A}$ are the total deposits in domestic banks (or $N_{t}^{A}=N_{1 t}^{A}+N_{2 t}^{A}$ ). For simplicity we assume that both deposits and the loans from the central bank (monetary transfers) are subject to reserve requirements. This assumption does not have any effect on the results.

The evolution of wealth for the household is given by

(5)

$$
\begin{aligned}
& M_{1, t+1}^{A}+\tilde{e}_{t+1} M_{1, t+1}^{B}=\left[M_{1 t}^{A}-N_{1 t}^{A}-P_{t}^{A} C_{1 t}^{A}\right] \\
& +\tilde{e}_{t+1}\left[M_{1 t}^{B}-N_{1 t}^{B}-P_{t}^{B} C_{1 t}^{B}\right]+W_{t}^{A} L_{1 t}+\frac{N_{1 t}^{A}}{q_{D t}^{A}}+\tilde{e}_{t+1} \frac{N_{1 t}^{B}}{{ }^{B}}{ }_{D t}^{B} \\
& +\left[P_{t}^{A} f\left(H_{t}^{A}\right)-\frac{{ }_{1 t}^{A}}{{ }^{A}}{ }_{L t}^{A}\right]+\left[B_{1 t}^{A}-W_{t}^{A} H_{t}^{A}\right]+V_{t}^{A}+S_{t}^{A}
\end{aligned}
$$

where $\bar{e}$ is the nominal exchange rate, and

$$
{ }^{A} D=\frac{1}{1+{ }^{A} D}
$$


(6b)

$$
{ }^{A} L=\frac{1}{1+{ }^{A} L}
$$

where ${ }^{A} D$ is the nominal interest rate on deposits, and ${ }^{i} L$ is the nominal interest rate on loans. Since we assume a competitive banking system it must hold that profits are zero or

$$
\left(1+\frac{i_{D}^{A}}{{ }^{A}}\right) N^{A}=\left(1+{ }^{i}{ }_{L}^{A}\right) B^{A}+\frac{R}{1-R} B^{A}-\left(1+{ }_{C B}^{A}\right) \Delta^{A}
$$

i.e. all revenues from the credit activity are redistributed to depositors in the form of interest payments.

Going back to (5), the first two terms of the right-hand side represent the cash left over after the transactions in the goods markets; similarly the last term $\left[{ }^{A} L-W^{A} H^{A}\right]$ is the cash left over in the firm after the payment of salaries. $W^{A} L_{1}$ is the salary received by the "worker" of the family; $\frac{N_{1}^{A}}{{ }^{A}{ }_{D}^{A}}$ and $\bar{e} \frac{N_{1}^{B}}{{ }^{B}}$ the gross return of domestic and foreign currency deposits; $\left[P^{A} f\left(H^{A}\right)-\frac{B^{A}}{q_{L}^{A}}\right]$ is the firm's profit. $\mathrm{V}_{\mathrm{t}}$ represents the lump sum transfer to the households while $S_{t}$ is the tax used to sterilize the transfer $\Delta_{t}$ to the banking system.

It is useful to renormalize all nominal variables in terms of the corresponding total money supplies $\left(M_{t}^{A}, M_{t}^{B}\right)$.

(8) ${ }^{A}{ }_{1 t}^{A}=\frac{M_{1 t}^{A}}{M_{t}^{A}} ; \quad m_{1 t}^{B}=\frac{M_{1 t}^{B}}{M_{t}^{B}} ; \quad n_{1 t}^{A}=\frac{N_{1 t}^{A}}{M_{t}^{A}} ; \quad n_{1 t}^{B}=\frac{M_{1 t}^{B}}{M_{t}^{B}}$; 


$$
\begin{aligned}
& b_{1 t}^{A}=\frac{B_{1 t}^{A}}{M_{1 t}^{A}} ; \quad p_{t}^{A}=\frac{P_{t}^{A}}{M_{t}^{A}} ; \quad p_{t}^{B}=\frac{P_{t}^{B}}{M_{t}^{B}} ; w_{t}^{A}=\frac{W_{t}^{A}}{M_{t}^{A}} ; \quad e_{t}=\tilde{e} \frac{M_{t}}{M_{t}^{A}} \\
& v_{t}^{i}=\frac{V_{t}^{i}}{M_{t}^{i}} ; \quad s_{t}^{i}=\frac{S_{t}^{i}}{M_{t}^{i}} ; \quad \delta_{t}^{A}=\frac{\Delta_{t}^{i}}{M_{t}^{i}} ;(i=A, B)
\end{aligned}
$$

In the following we restrict the analysis to stationary equilibria and thus drop the time subscript. Under this assumption we present the optimization problem faced by the household of country 1 in terms of the normalized variables:

(9) $V\left(m_{1}^{A}+e m_{1}^{B}\right)=\max U\left(c_{1}^{A}, c_{1}^{B}\right)+Z\left(1-L_{1}\right)+\beta V\left(m_{1}^{A^{\prime}}+e^{\prime} m_{1}^{B^{\prime}}\right)$

$$
\begin{gathered}
c_{1}^{A}, c_{1}^{B}, n_{1}^{A},{ }^{B}{ }_{1} \\
L_{1}, H^{A}, b_{1}^{A}
\end{gathered}
$$

subject to

$$
m_{1}^{A}-n_{1}^{A} \geq p^{A} c_{1}^{A}
$$

$$
m_{1}^{B}-n_{1}^{B} \geq p^{B} c_{1}^{B}
$$

$$
b_{1}^{A} \geq w^{A} H^{A}
$$

and where

$$
\text { (11) } m_{1}^{A^{\prime}}+e^{\prime} m_{1}^{B^{\prime}}=\frac{\left[m_{1}^{A}-n_{1}^{A}-p^{A} c_{1}^{A}\right]}{\left(1+X^{A}\right)}+e^{\prime} \frac{\left[m_{1}^{B}-n_{1}^{B}-p^{B} c_{1}^{B}\right]}{\left(1+X^{B}\right)}
$$




$$
\begin{gathered}
+\frac{w^{A} L_{1}}{1+X^{A}}+\frac{n_{1}^{A}}{\left(1+X^{A}\right) q_{D}^{A}}+e^{\prime} \frac{{ }_{n}^{B}}{\left(1+X^{B}\right) q_{D}^{B}} \\
+\left[p \frac{f\left(H^{A}\right)}{\left(1+X^{A}\right)}-\frac{b_{1}^{A}}{\left(1+X^{A}\right) q_{L}^{A}}\right]+\left[\frac{b_{1}^{A}}{\left(1+X^{A}\right)}-\frac{w^{\prime} H^{A}}{\left(1+X^{A}\right)}\right] \\
+\frac{v^{A}}{1+X^{A}}+\frac{s^{A}}{1+X^{A}}
\end{gathered}
$$

where' indicates next period values, and $X^{i}$ is the rate of growth of currency i: $\left[\left(M_{t+1}^{i}-M_{t}^{i}\right) / M_{t}^{i}\right]$.

Defining $\lambda_{1}, \lambda_{2}$ and $\lambda_{3}$ the Lagrange multipliers associated with $(10 a, b, c)$ respectively (which from now on we assume hold with equality), the first-order conditions of the problem can be written as:

$c_{1}^{A}$

$$
\frac{U_{A}}{p^{A}}=\lambda_{1}+\beta \frac{V_{1}^{\prime}}{\left(1+X^{A}\right)}
$$

(12b)

$$
c_{1}^{B}
$$

$$
\frac{U_{B}}{p^{B}}=\lambda_{2}+e^{\prime} \beta \frac{V_{1}^{\prime}}{\left(1+X^{B}\right)}
$$

$$
\frac{\beta V_{1}^{\prime}}{\left(1+X^{A}\right)}\left[\frac{1}{{ }^{A} D}-1\right]=\lambda_{1}
$$

(12c)

$$
n_{1}^{A}
$$


(12d)

$$
n_{1}^{B}
$$$$
\frac{\beta e^{\prime} V_{1}^{\prime}}{\left(1+X^{B}\right)}\left[\frac{1}{{ }^{B}}-1\right]=\lambda_{2}
$$

(12e)

$L_{1}:$

$$
z_{1}=w^{A} \beta \frac{V_{1}^{\prime}}{\left(1+X^{A}\right)}
$$

(12f)

$H^{A}:$

$$
\frac{\beta V_{1}^{\prime}}{\left(1+X^{A}\right)}\left[p^{A} f_{1}-w^{A}\right]=w^{A} \lambda_{3}
$$

(12g)

$$
b_{1}^{A}:
$$

$$
\frac{\beta V_{1}^{\prime}}{\left(1+X^{A}\right)}\left[\frac{1}{{ }^{A}}-1\right]=\lambda_{3}
$$

In addition the envelope conditions are:

(12h)

$$
\frac{U_{A}}{p^{A}}=V_{1}
$$

$$
\frac{U_{B}}{e_{p}^{B}}=V_{1}
$$

Notice from $(12 c, g)$ that

$$
\frac{\lambda_{1}}{{ }^{i} D}=\frac{\lambda_{3}}{{ }^{i} L}
$$

Since the value of cash in the goods market is given by $\lambda_{1}$ and the value of cash in the financial market is given by $\lambda_{3}$, condition (13) expresses 
the household policy of choosing $\mathrm{n}$ so that the value of currency is the same in the goods market and in the financial market (after the monetary injection has occurred).

Substituting (12c) into (12a),

$$
\frac{U_{A}}{P_{A}}=\beta \frac{V_{1}^{\prime}}{\left(1+X^{A}\right) q_{D}^{A}} .
$$

Using the envelope condition (12h) (and imposing stationarity $V_{1}^{\prime}=$ $V_{1}$ ) we obtain

$$
{ }^{A} D=\frac{\beta}{\left(1+X^{A}\right)} .
$$

Given that in equilibrium $X^{A}$ is equal to the rate of inflation of currency $A$, condition (15a) is the usual steady-state condition

$$
r_{D}^{A}=\rho
$$

where $r_{D}^{A}$ is the real rate (of interest) on deposits (in currency $A$ ), and $\rho$ is the utility rate of time preference.

It can be also observed that condition (14) is the standard intertemporal optimization condition implying the the household equalizes the marginal utility of consumption at time $t$ to the marginal utility of consumption at time $t+1$ times the ratio $\left(1+r_{D}^{A}\right) /(1+\rho)$.

Analogously from (12b, d) we obtain

$$
{ }^{B}{ }_{D}^{B}=\frac{\beta}{\left(1+X^{B}\right)}
$$




$$
r_{D}^{B}=\rho .
$$

From (12e, h and 15a), the wage rate is given by:

$$
w^{A}=\frac{z_{1} p^{A}}{{ }^{A} U_{D}} .
$$

Substituting into (12f) and using the envelope (12h), we get

$$
\lambda_{3}=\left[q_{D}^{A} \frac{U_{A}}{p}\right]^{2}\left[p^{A} f_{1}-\frac{Z_{1}{ }^{A}}{q_{D}^{A} U_{A}}\right] \frac{1}{Z_{1}} .
$$

Substituting into (12g) and using the envelope (12h),

$$
\frac{Z_{1}}{U_{A}}=f_{1} q_{D^{q}}^{A}{ }^{A} .
$$

This is similar to the relationship found by Fuerst [1989], the main difference being we have two $q$ 's i.e. two interest rates (borrowing and lending) instead of only one. This specification clarifies the two channels through which changes in interest rates affect real activity. First, for the household leisure is a good that can be purchased without cash. An increase in ${ }_{D}$ (decrease of $q_{D}$ ), i.e. the nominal interest rate faced by individuals, implies an increase in inflation tax and thus leads to a reduction of market activities (labor supply) and an increase in leisure (whose relative cost has fallen). An increase in ${ }_{L}$ (decrease in $q_{L}$ ) represents an increase in costs for the firm since it uses credit to hire workers. Therefore higher loan rates will lead to a reduction in the demand for labor. The issue will be whether ${ }^{i} D$ and ${ }_{i}$ rise or fall with 
an increase in $X$.

\section{A Equilibrium}

To simplify the analysis we assume the following functional specifications:

$$
U\left(c_{i}^{A}, c_{i}^{B}\right)=\log c_{i}^{A}+\gamma \log c_{i}^{B} \quad i=1,2
$$

$$
f\left(H_{j}\right)=\theta_{j} H_{j}^{\alpha}
$$

$$
j=A, B
$$

$$
Z\left(1-L_{j}\right)=1-L_{j}
$$

Equilibrium in the labor market requires (concentrating again on country 1) that labor supply and labor demand are equal or

$$
H_{j}=L_{i}
$$

and thus (20b) becomes

$$
f\left(L_{i}\right)=\theta_{j} L_{i}^{\alpha}
$$

Equilibrium in the good market implies that the total consumption of country 1's good is equal to its supply :

$$
c_{1}^{A}+c_{2}^{A}=\theta_{A} L_{1}^{\alpha} \text {. }
$$

Equilibrium in the credit market requires that the demand for loans from the firms is equal to its supply by the banks:

$$
{ }^{b_{1}}{ }_{1} \equiv b^{A}=\left(n_{1}^{A}+n_{2}^{A}+\delta^{A}\right)(1-R) \equiv\left(n^{A}+\delta^{A}\right)(1-R)
$$


(23) together with (10c) imply that the wage rate is given by the firms' borrowing divided by their labor demand:

$$
w^{A}=\frac{\left(n^{A}+\delta^{A}\right)(1-R)}{L_{1}} .
$$

(23) together with (7) (renormalized) implies:

$$
{ }^{i} L=\frac{n^{A}+\mathrm{s} \delta^{A}}{(1-R)\left(n^{A}+\delta^{A}\right)}{ }^{A} D
$$

where we have defined the discount rate in terms of the deposit rate

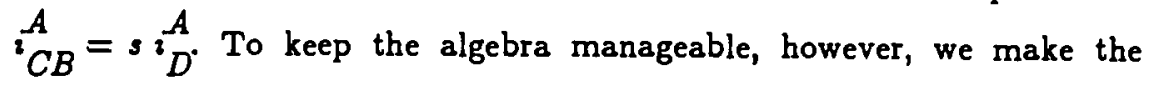
assumption that:

$$
R\left(n^{A}+\delta^{A}\right)=\left(1+{ }^{A} C B\right) \delta^{A}
$$

and thus ( $\left.7^{\prime}\right)$ reduces to:

$$
{ }^{A}{ }_{L}^{A}=\frac{\left(n^{A}+\delta^{A}\right)(1-R)}{n^{A}} q_{D}^{A} .
$$

The assumption (7") has no consequence on the qualitative results, and in the appendix we provide the solution of the model under the general specification ( $\left.7^{\prime}\right)$. It is interesting to notice that ( $\left.7^{\prime \prime}\right)$ implies a negative relationship between the discount rate $\left(i_{C B}\right)$ and the credit expansion $\left(\delta^{A}\right)$, i.e.:

$(7 ' \prime)$

$$
{ }_{C B}^{A}=\frac{R n^{A}-\delta^{A}(1-R)}{\delta^{A}}
$$

In this particular experiment, therefore, a credit expansion can be 
thought of as a combination of an increase in credit available to the banking system and a reduction in the discount rate. While we find this assumption appealing, it is of no consequence for our results. The same conclusions can be obtained assuming that $\delta^{A}$ and ${ }^{i} C B$ are set independently (we refer the reader to the appendix for this general case). Using the steady $\rightarrow$ state condition (15a),

$$
{ }_{L}^{A}=\beta \frac{\left(n^{A}+\delta^{A}\right)(1-R)}{n^{A}\left(1+X^{A}\right)}
$$

Comparing (25') and (15a) we notice that for large enough $R{ }_{{ }^{i} D}^{A}<{ }^{A} L$.

Equilibrium in the money market requires the equality between money demand and money supply

$$
m_{1}^{A}+m_{2}^{A}=m^{A}=1
$$

where $m=1$ is the steady state normalized money supply. (26) together with $(10 a-10 b)$ inplies that the price of the domestic good is given by the ratio of money available in the goods market to the level of output:

$$
p^{A}=\frac{1-n^{A}}{\theta_{A} L_{1}^{\alpha}} .
$$

The log utility specification implies that equilibrium consumption is given by

$$
c_{1}^{A}=\frac{Y^{A}}{1+\gamma}=\frac{{ }_{A} L_{1}^{\alpha}}{1+\gamma}
$$

$$
c_{2}^{A}=\frac{\gamma Y^{A}}{1+\gamma}=\frac{{ }^{0}{ }_{A} L_{1}^{\alpha}}{1+\gamma}
$$




$$
c_{1}^{B}=\frac{Y^{B}}{1+\gamma}=\frac{{ }_{B}{ }_{B} L_{2}^{\alpha}}{1+\gamma} ; \quad \quad c_{2}^{B}=\frac{\gamma Y^{B}}{1+\gamma}=\frac{{ }^{\gamma}{ }_{B} L_{2}^{\alpha}}{1+\gamma}
$$

The envelope condition (12h) together with (27) and (28) implies

$$
V_{1}=\frac{1+\gamma}{1-n^{A}} .
$$

Using (24) and (29) into (12e) we obtain the labor supply schedule

$$
L_{1}=\frac{n^{A}+\delta^{A}}{\left(1+X^{A}\right)} \beta \frac{1+\gamma}{\left(1-n^{A}\right)}(1-R) .
$$

In (30) the supply of labor is a function of $n^{A}$ (the share of money balances deposited in the banking system) that is an endogenous variable. Using (15a, 25' and 28 ) into (19) we obtain

$$
L_{1}=\alpha(1+\gamma)\left[\frac{\beta}{1+X^{A}}\right]^{2} \frac{\left(n^{A}+\delta^{A}\right)}{n^{A}}(1-R) .
$$

Equating (30) to (31) we can solve for $n^{A}$ as:

$$
n^{A}=\frac{\alpha \beta}{1+X^{A}+\alpha \beta} .
$$

Therefore $n^{A}$ is a negative function of $X^{A}$.

Substituting (32) into (25') we have:

$$
{ }_{L}^{A}=\left[\frac{\delta}{\alpha}+\beta \frac{1+\delta^{A}}{1+X^{A}}\right](1-R) .
$$

while, from (15a):

$$
q_{D}^{A}=\frac{\beta}{1+X^{A}}
$$


We can now analyze the effects of monetary injections on interest rates. To concentrate on the pure effects of an increase in the rate of growth of money $X^{A}$ assume that $R=0$ and $\delta^{A}=0$. Then:

$$
{ }^{A}{ }_{D}^{A}={ }^{q}{ }_{L}^{A}=\frac{\beta}{1+X^{A}}
$$

In this case an increase in the rate of growth of money $X^{A}$ (an increase in steady state inflation) leads to a corresponding increase in nominal interest rates (both borrowing and lending rates).

Consider now the other case in which of money is constant $\left(X^{A}=0\right)$ and the monetary injections take only the form of a redistributive transfer (an increase in $\delta^{A}$ ). In this case:

$$
{ }^{A}{ }_{L}^{A}=\frac{\delta^{A}+\alpha \beta\left(1+\delta^{A}\right)}{\alpha}(1-R)
$$

Then an increase in the monetary injection $\delta^{A}$ (that leaves the money supply unchanged) will reduce the lending rate ${ }^{A} L$ (increase $q_{L}^{A}$ ) while it will leave the deposit rate ${ }^{A} D$ unchanged.

In general we get that:

$$
\begin{aligned}
& \frac{\partial{ }_{L}^{A}}{\partial \delta^{A}}=\left[\frac{1}{\alpha}+\frac{\beta}{1+X^{A}}\right](1-R)>0 \\
& \frac{\partial q_{L}^{A}}{\partial X^{A}}=-\frac{\beta\left(1+\delta^{A}\right)(1-R)}{\left(1+X^{A}\right)^{2}}<0
\end{aligned}
$$




$$
\frac{\partial{ }^{q}{ }_{L}^{A}}{\partial R}=-\left[\frac{\delta^{A}}{\alpha}+\frac{\beta\left(1+\delta^{A}\right)}{\left(1+X^{A}\right)}\right]<0
$$

In summary: an increase in nominal transfers to households increases the inflation rate and both interest rates while an increase in the transfers (central bank loans) to the banking system decreases the lending rate but leaves the deposit rate unchanged. Finally an increase in the required reserve ratio increases the lending rate but leaves the deposit rate unchanged.

We can now consider the effects of these monetary injections on the labor and output decisions of firms and households. In equilibrium, substituting (32) into either (30) or (31), we get

$$
L_{1}=(1+\gamma)(1-R) \frac{\beta}{\left(1+X^{A}\right)}\left[\delta^{A}+\alpha \beta \frac{\left(1+\delta^{A}\right)}{\left(1+X^{\mathrm{A}}\right)}\right]
$$

Therefore:

$$
\frac{\partial L_{1}}{\partial X^{A}}<0
$$

$$
\frac{\partial L_{1}}{\partial \delta^{A}}>0
$$

$$
\frac{\partial L_{1}}{\partial R}<0
$$

It can be observed that an increase in the rate of growth of money $\left(X^{A}\right)$ (an increase in the inflation rate) leads to an increase in the "inflation tax" and a reduction in the employment of labor. In fact, the increase in the lending rate leads firms to reduce their labor demand 
while the increased inflation tax leads households to reduce their labor supply (increase their demand for leisure).

Conversely, a monetary injection in the form of a transfer to the banking system $\left(\delta^{A}\right)$ reduces the lending rate. The reduction of the firms' borrowing costs following this monetary injection leads the firms to demand more labor. Also, as will be seen below, an increase in $\delta^{A}$ leads to an increase in the real wage that leads workers to increase their supply of labor.

In order to understand better the labor and output effects of these different types of monetary injections we can look at the behavior of nominal and real wages. Substituting (32) and (34) into (24) we obtain the nominal wage $w^{A}$ as:

$$
w^{A}=\frac{\left(1+X^{A}\right)^{2}}{\beta(1+\gamma)\left(1+X^{A}+\alpha \beta\right)}
$$

which is a positive function of $X^{A}$ but is independent of $\delta^{A}$.

Using (32) and (34) in (27) we can rewrite the price level as:

(27)

$$
p^{A}=\frac{\left(1+X^{A}\right)^{2 \alpha+1}}{\theta_{A}\left(1+X^{A}+\alpha \beta\right)\left\{(1-R)(1+\gamma) \beta\left[\alpha \beta+\delta^{A}\left(1+X^{A}+\alpha \beta\right]\right\}^{\alpha}\right.}
$$

Dividing (35) by (27') we the get the real wage as:

$$
\frac{w^{A}}{p^{A}}=\theta_{A}\left[\frac{1+X^{A}}{\beta(1+\gamma)(1-R)}\right]^{1-\alpha}\left[\delta^{A}+\frac{\alpha \beta\left(1+\delta^{A}\right)}{\left(1+X^{A}\right)}\right]^{a}
$$

Given that wage receipts cannot be used until the next period, a more appropriate definition of real wage is given by: 
$\left(35^{\prime \prime}\right)$

$$
\frac{w^{A}}{p^{A^{\prime}}}=\theta_{A}\left[\frac{\beta(1+\gamma)(1-R)^{\alpha}}{1+X^{A}}\left[\delta^{A}+\frac{\alpha \beta\left(1+\delta^{A}\right)}{\left(1+X^{A}\right)}\right]^{a}\right.
$$

Given the solution (35") for the real wage it can be easily shown that:

$$
\frac{\partial\left(w^{A} / p^{A j}\right)}{\partial \delta^{A}}>0, \quad \frac{\partial\left(w^{A} / p^{A}\right)}{\partial X^{A}}<0
$$

The above results imply that an increase in $\delta^{A}$ will lead to an increase in the real wage and therefore to an increase in the supply of labor; while an increase in $\mathrm{X}^{A}$ (an increase in the inflation rate) will reduce the real wage and lead to a greater demand for leisure and a lower supply of labor.

The envelope conditions (12h) and (12i) give the nominal exchange rate that equilibrates the goods market as

$$
e=\frac{p_{A}}{p_{B}} \frac{c_{1}^{A}}{c_{1}^{B}} \gamma
$$

Substituting (27) and (28),

$$
e=\frac{1-n^{A}}{1-n^{B}} \gamma=\frac{\left(1+\alpha \beta+X^{B}\right)}{\left(1+\alpha \beta+X^{A}\right)} \frac{\left(1+X^{A}\right)}{\left(1+X^{B}\right)} \gamma
$$

while the real exchange rate is given by

$$
\begin{aligned}
& \delta^{A}+\alpha \beta \frac{1+\delta^{A}}{1+X^{A}} \\
& \text { (38) } r e=e \frac{{ }^{P_{A}}}{{ }_{P_{B}}}=\gamma \frac{{ }^{\theta} A}{\theta_{B}}\left[\frac{1+X^{A}}{\delta^{A}+\alpha \beta \frac{1+\delta^{A}}{1+X^{A}}}\right]\left[\frac{\left(1+X^{A}\right)}{\left(1+X^{B}\right)}\right]^{a} \text {. }
\end{aligned}
$$


It can be easily shown that:

$$
\frac{\partial e}{\partial X^{A}}<0, \quad \frac{\partial r e}{\partial \delta^{A}}>0
$$

Therefore a monetary injection that does not affect the rate of growth of money (an increase in $\delta^{A}$ ) generates a real depreciation of the exchange rate. Conversely, in the case of an increase in the rate of monetary growth $\left(X^{A}\right)$ the real exchange rate will appreciate. For what concerns the nominal exchange rate, (37) implies that an increase in $\delta^{A}$ does not affect the exchange rate. The reason for this result is quite clear; this credit expansion does not lead to a money supply increase but only to an output expansion. This increase in output has ambiguous effects on the exchange rate: on one side the negative terms of trade effect should lead to a nominal depreciation; on the other, the money demand effect, leads to a fall in domestic prices and a nominal appreciation. As it is well known, in the Cobb-Douglas utility case these two effects cancel out each other and leave the nominal exchange rate unchanged. On the other side, as intuitively expected, (37) shows that an increase in the rate of growth of money $X^{A}$ leads to a nominal depreciation of the domestic currency.

The reasons for the appreciation of the real exchange rate in the case of an increase in the rate of growth of money are similarly clear. As seen above, an increase in the inflation rate leads to a reduction in labor supply and demand, a fall in employment and a reduction in output. In equilibrium, the fall in domestic output leads to an improvement in the domestic terms of trade, i.e. a real appreciation of the currency. 3

It should also be observed that our results regarding the output effects of monetary injections are different from the ones obtained by 
Fuerst. In Fuerst's analysis, there is no distinction between borrowing and lending interest rates, nor between monetary injections leading to higher monetary growth and those that are only redistributive. In the case of an increase in $X$, our analysis is similar to Fuerst's since an increase in monetary growth leads to higher interest rates which reduce work effort, labor demand and output. However, in the case of an increase in credit, the monetary injection leads to the fall in the lending rate and an increase in the demand for labor by the firms. The increase in $\delta^{A}$ also leads to an increase in the wage rate that stimulates labor effort.

Finally, while monetary injections affect the level of economic activity in the country in which the injection occurs, they do not affect the level of output in the other country. In fact, changes in monetary policy affect the real interest rates faced by borrowing firms. However, since firms pay workers in domestic currency, in equilibrium they will borrow only from their domestic banks. Therefore, changes in interest rates in the other country will not affect their borrowing rates nor their demand for labor. It should, however, be observed that, while monetary policy does not have the usual "beggar my neighbor" effects on foreign output, it will affect foreign consumption. In fact, changes in domestic output have terms of trade effects that will affect the consumption levels and the welfare of the other country.

This independence of foreign output from domestic monetary policies, however, depends on the assumption of separability of consumption and leisure in the utility function. In fact, while domestic monetary policies affect foreign consumptions level through their terms of trade effects, this change in consumption does not affect the marginal utility of leisure and therefore has no effect on the foreign labor supply. 
Under a more general, non-separable specification of the utility function, these consumption effect will lead to a change in labor supply and to foreign output effects of domestic money disturbances.

\section{B Welfare}

We will consider now the effects of monetary injections on the level of welfare. If we substitute the equilibrium values of consumption and work effort in the utility function, we obtain that the steady $\rightarrow$ state level of utility is given by

$$
\begin{aligned}
U^{A}=A & +\alpha\left[\log \left[\delta^{A}+\frac{\alpha \beta\left(1+\delta^{A}\right)}{\left(1+X^{A}\right)}\right]-\log \left(1+X^{A}\right)\right] \\
& +\gamma \alpha\left[\log \left[\delta^{B}+\frac{\alpha \beta\left(1+\delta^{B}\right)}{\left(1+X^{B}\right)}\right]-\log \left(1+X^{B}\right)\right] \\
& -\beta \frac{1+\gamma}{1+X^{A}}(1-R)\left[\delta^{A}+\frac{\alpha \beta\left(1+\delta^{A}\right)}{\left(1+X^{A}\right)}\right]
\end{aligned}
$$

where $A$ is a constant

$$
A=1+\log \frac{{ }^{\theta} A}{1+\gamma}+\log \frac{{ }^{\theta} \mathrm{B}}{1+\gamma}+\alpha(1+\gamma) \log \beta(1+\gamma)(1-R) .
$$

Notice first that monetary injections to the foreign banking system always increase domestic welfare since they increase foreign output, improve the domestic terms of trade and increase the domestic consumption of foreign goods:

$$
\frac{\partial U^{A}}{\partial \delta^{B}}=>0 .
$$


Conversely, increases in the foreign rate of growth of money always decrease domestic welfare since they decrease foreign output, worsen the domestic terms of trade and reduce the domestic consumption of foreign goods:

$$
\frac{\partial U^{A}}{\partial X^{B}}=<0
$$

The welfare effect of a domestic increase in monetary growth $X^{A}$ is ambiguous. This is because, while the decrease in output generates a reduction in domestic consumption, it also implies a reduction in work effort. More specifically, in the case in which $\delta^{A}=\delta^{B}=0$, we get that:

$$
\frac{\partial U^{A}}{\partial X^{A}}=<0 \quad \text { if }\left(1+X^{A}\right)>\beta[(1+\gamma)(1-R)]^{1 / 2} .
$$

The intuition for the result is quite simple: as the rate of growth of money becomes greater, domestic consumption falls while leisure increases; since the marginal utility of leisure is constant while the marginal utility of consumption is increasing as consumption falls, a rate of growth of money above a critical value leads to a reduction in welfare.

We can also observe that, in the case of $R=0$ and a closed economy ( $\gamma=0$ so that the foreign good is not consumed) we obtain that the level of monetary growth that maximizes the steady-state level of utility is given by the Friedman zero nominal interest rate rule:

$$
1+\bar{X}^{A}=\beta
$$

Thus for $X^{A}>\bar{X}^{A}$ (i.e. inflation rates greater than the negative of the rate of time preference), higher levels of monetary growth correspond to lower levels of utility. 
In the general case where the economy is open ( $\gamma$ differs from zero), the Friedman rule will not be optimal and the inflation rate that maximizes steady state utility $\left(\beta[(1+\gamma)(1-R)]^{1 / 2}\right)$ will be higher than the one implied by the Friedman rule. The reason for this result is simple: relative to the Friedman rule, an increase in the inflation rate will lead to a fall in output, an improvement in the terms of trade of the country and an increase in consumption. It is the externality deriving from the ability of the country to improve its terms of trade that accounts this non-optimality of the zero nominal interest rate rule.

This externality also implies interesting strategic interactions. In particular, in a non-cooperative game-theoretic set-up, the Nash equilibrium will imply that the non-cooperative inflation rate will be higher than optimal as each country tries to increase the inflation rate in order to engineer a terms of trade improvement and a welfare increase. Conversely, the cooperative global optimum for the world economy will be again equal to the Friedman zero nominal interest rate rule since the two countries will internalize the terms of trade externality and recognize that a competitive terms of trade improvement is not possible.

We finally consider the effects of domestic monetary injections to the banking system on the domestic welfare. It can be shown that, if $X^{A}=X^{B}=0$ :

$$
\frac{\partial U^{A}}{\partial \delta^{A}}=>0
$$$$
\text { if } \delta^{A}<\frac{\alpha\left[1-\beta^{2}(1+\gamma)(1-R)\right]}{\beta(1+\gamma)(1+\alpha \beta(1-R))}
$$

The explanation for the result is the following: as the monetary injection becomes greater, domestic output goes as well as consumption increase while leisure decreases; since the marginal utility of leisure is constant while the marginal utility of consumption is decreasing as consumption 
increases a monetary injection above a critical value leads to a reduction in welfare.

\section{A MODEL WITH CAPITAL}

In this section we change the specification of production function to allow for investment decisions. To simplify the analysis we do not model explicitly the labor/leisure decision. Specifically the instantaneous utility function is now given by:

$$
u_{i}=u\left(c_{i}^{A}, c_{i}^{B}\right)=\log \left(c_{i}^{A}\right)+\gamma \log \left(c_{i}^{B}\right) .
$$

In addition to labor which is assumed to be inelastically supplied and thus not explicitly considered, production requires intermediate goods (capital goods). These intermediate goods consist of consumption goods purchased and stored by the firm in the previous period. Formally

$$
Y_{A}=f^{A}\left(K_{1}^{A}\right)=\theta_{A} K^{A \alpha}
$$

$$
Y_{B}=f^{B}\left(K_{2}^{B}\right)={ }_{B} K^{B \alpha}
$$

where $K^{i}$ are the consumption goods stored in the previous period.

Goods last only for one period: they can be used in next period production, but completely depreciate after that. Therefore, while we have investment decisions, we do not have capital accumulation. Notice also that only domestic goods are used to produce domestic products. We will relax this assumption in the next section. Country 1's household optimization problem is now given by

$$
V\left(m_{1}^{A}+e m_{1}^{B}, K^{A}\right)=\max U\left(c_{1}^{A}, c_{1}^{B}\right)+\beta V\left(m_{1}^{A^{\prime}}+e^{\prime} m_{1}^{B^{\prime}}, K^{A^{\prime}}\right)
$$


subject to

$$
m_{1}^{A}-n_{1}^{A} \geq p^{A} c_{1}^{A}
$$

$$
m_{1}^{B}-n_{1}^{B} \geq p^{B} c_{1}^{B}
$$

$$
b_{1}^{A} \geq p^{A} K_{1}^{A^{\prime}}
$$

$$
Y_{A}=\theta_{A} K^{A \alpha}
$$

and where

$$
\text { (44) } \begin{aligned}
m_{1}^{A^{\prime}}+e^{\prime} M_{1}^{B^{\prime}}=\frac{\left[m_{1}^{A}-n_{1}^{A}-p^{A} c_{1}^{A}\right]}{\left(1+X^{A}\right)}+e^{\prime} \frac{\left[m_{1}^{B}-n_{1}^{B}-p^{B} c_{1}^{B}\right]}{\left(1+X^{B}\right)} \\
+\frac{n_{1}^{A}}{\left(1+X^{A}\right) q_{D}^{A}}+\frac{e^{\prime} n_{1}^{B}}{\left(1+X^{B}\right) q_{D}^{B}}+\left[\frac{p^{A} Y^{A}}{\left(1+X^{A}\right)}-\frac{b_{1}^{A}}{\left(1+X^{A}\right) q_{L}^{A}}\right]+ \\
{\left[\frac{b_{1}^{A}}{1+X^{A}}-\frac{p^{A} K^{A^{\prime}}}{1+X^{A}}\right]+\frac{v^{A}}{\left(1+X^{A}\right)}+\frac{s^{A}}{\left(1+X^{B}\right)} }
\end{aligned}
$$

(43 c) is the cash in advance constraint for the firm: the firm has to borrow funds from the banking system in order to buy the intermediate (capital) goods to be used in production. The first—order conditions are identical to the ones obtained previously $(12 a-k)$ except that instead of $(12 e, f)$ we now have 
(45a)

$$
K^{A}: \quad \beta V_{2}^{\prime}-\beta V_{1}^{\prime} \frac{p^{A}}{\left(1+X^{A}\right)}=\lambda_{\rho^{p}}{ }^{A}
$$

and the envelope condition for the intermediate good

$$
V_{2}^{\prime}=\beta V_{1}^{\prime \prime} p^{A^{\prime}} \frac{f_{1}\left(K^{A^{\prime}}\right)}{\left(1+X^{A^{\prime}}\right)}
$$

where" "refers to two-periods-ahead variables.

$(45 \mathrm{a}, \mathrm{b})$ together imply

$$
\beta^{2} \beta V_{1}^{\prime \prime} \frac{p^{A^{\prime} f_{1}^{\prime}}}{\left(1+X^{A^{\prime}}\right)}=p^{A}\left[\frac{\beta}{\left(1+X^{A}\right)} V_{1}^{\prime}+\lambda_{3}\right]
$$

Notice that as before, the steady-state condition

$$
{ }^{A} D=\frac{\beta}{1+X^{A}}
$$

holds.

\section{A Equilibrium}

The equilibrium condition in the market for good $A$ is given by

$$
c_{1}^{A}+c_{2}^{A}+K^{A^{\prime}} \equiv c^{A}+K^{A^{\prime}}=Y_{A} \equiv \theta_{A} K^{A \alpha} .
$$

As before, equilibrium in the credit market requires

$$
b_{1}^{A} \equiv b^{A}=\left(n^{A}+\delta^{A}\right)(1-R)
$$

which together with the "credit-in $-a d v a n c e " ~ c o n s t r a i n t ~(43 c)$ implies 


$$
K^{A^{\prime}}=\frac{n^{A}+\delta^{A}}{p^{A}}(1-R) .
$$

Equilibrium in the money market

$$
m_{1}^{A}+m_{2}^{A}=m^{A}=1
$$

and the cash-in-advance constraints in the good markets imply

$$
c_{1}^{A}+c_{2}^{A}=c^{A}=\frac{1-n^{A}}{p^{A}} .
$$

Substituting (48) and (49) into (47), the nominal price of $A$ is given by

$$
p^{A}=\frac{1+\delta^{A}-R\left(n^{A}+\delta^{A}\right)}{\theta_{A} K^{A \alpha}}
$$

Recalling that under the Cobb-Douglas assumption savings are constant and thus $K^{A^{\prime}}=K^{A}, c_{1}^{A^{\prime}}=c_{1}^{A}$ and that in the stationary equilibrium $p^{A^{\prime}}=p^{A},(46)$ can be rewritten as

$$
\frac{\beta^{2}}{p^{A} c_{1}^{A}} \frac{p_{1}^{A} f_{1}}{1+X^{A}}=p^{A}\left[\frac{\beta}{1+X^{A}} \frac{1}{p^{A} c_{1}^{A}}+\lambda_{3}\right] .
$$

Substituting $\lambda_{3}$ from (12g) (and using the envelope conditions) we have

$$
\beta f_{1}\left(K^{A}\right)=\frac{1}{{ }^{A} L} \equiv 1+{ }^{A} L
$$

that is the optimal amount of intermediate good is a negative function of the lending interest rate. This is the salient feature of this cash-in-advance, credit-in-advance framework. As in the previous 
model a higher rate of monetary injection to the banking sector will reduce the lending interest rate and thus increases the steady-state level of capital. Specifically from (48) and (50) we obtain

$$
K^{A}=\left[\theta \frac{\left(n^{A}+\delta^{A}\right)-R\left(n^{A}+\delta^{A}\right)}{\left(1+\delta^{A}\right)-R\left(n^{A}+\delta^{A}\right)}\right]^{\frac{1}{1-\alpha}} .
$$

From (25', 52 and 53) we obtain that the share of money $A$ deposited at the financial intermediary is given by

$$
n^{A}=\frac{\beta^{2} \alpha\left[1+(1-R) \delta^{A}\right]}{1+X^{A}+\alpha \beta^{2} R}
$$

Substituting (54) into (53) we get the equilibrium value of $K^{A}$ :

$$
K^{A}=\left[\theta_{A}(1-R) \frac{\alpha \beta^{2}\left(1+\delta^{A}\right)+\delta^{A}\left(1+\delta^{A}\right)}{\left(1+X^{A}\right)\left(1+\delta^{A}(1-R)\right)}\right]^{\frac{1}{1-\alpha}}
$$

From (53'), the effect on the steady - state capital stock of increased monetary injections to the banking system is always positive, i.e.:

$$
\frac{\partial K^{A}}{\partial \delta^{A}}>0
$$

In fact, increases in $\delta^{A}$ reduce the lending rate ${ }^{A} L$ and lead firms to demand greater capital (intermediate good). This increased steady state capital stock implies a greater level of output.

Conversely, increases in the rate of growth of money coming from increases in lump sum transfers to households $\left(X^{A}\right)$ increase 
interest rates, decrease the firms' demand for capital and lead to a steady state fall in the capital stock and output. In fact, from (53') it can be shown that:

$$
\frac{\partial K^{A}}{\partial X^{A}}<0
$$

These results are quite similar to those obtained in the model with labor supply: in both models, increase in monetary injections to the banking system (that leave unchanged the money supply) lead to increases in domestic output; while monetary transfers to the households that lead to an increase in money growth lead to a reduction in domestic output.

\section{B Welfare}

As before, while changes in $X^{A}$ and $\delta^{A}$ lead to changes in the level of output, it does not necessarily follow that welfare will also be higher. Unlike section 3, however, domestic and foreign monetary growth enter symmetrically in the utility. This is intuitive given that work effort is not explicitly considered in this formulation. The reason why higher $X$ 's and $\delta$ 's do not necessarily increase utility is that while they always change output, they do not necessarily increase consumption. Given the decreasing returns to scale, beyond a certain level the marginal product of the intermediate good falls below one and thus the output available for consumption decreases. In particular, assuming for simplicity that $R=0$, we get that:

$$
\frac{\partial U^{A}}{\partial \delta^{i}}>0 \quad \text { if } \delta^{i}<\frac{\alpha\left[1+X^{i}-\beta^{2}\right]}{\beta^{2}+(1-\alpha)\left(1+X^{i}\right)} \quad(i=A, B)
$$


i.e.the level of $\delta^{i}$ that maximizes domestic utility is:

$$
\tilde{\delta}^{i}=\frac{\alpha\left[1+X^{i}-\beta^{2}\right]}{\beta^{2}+(1-\alpha)\left(1+X^{i}\right)}
$$

while values of $\delta^{i}$ greater than $\tilde{\delta}^{i}$ will reduce steady state consumption and utility. Similarly, considering the effects of the $X^{i}$ 's on steady state welfare and assuming, for simplicity, that $R=0$ we get that the level of $X^{i}$ that maximizes steady state welfare is given by:

$$
X^{i}=\frac{\alpha \beta^{2}\left(1+\delta^{i}\right)}{\alpha-(1-\alpha) \delta^{i}}
$$

\section{THE INTERNATIONAL TRANSMISSION OF MONETARY}

\section{SHOCKS: A MODEL WITH TWO INTERMEDLATE PRODUCTS}

The previous two sections stressed how monetary policies affect welfare not only domestically but world-wide. By altering the level of domestic output, domestic monetary injections change the terms of trade and thus affect not only domestic consumption but foreign consumption also. One possible weakness of the model so far is that the international transmission of policies occurs only through the effect on consumption while foreign output is not affected. In this section we extend the analysis to allow for this type of direct effect. To do this we modify the model of Section 4 by assuming that production requires both domestic and foreign goods as intermediate products. That is

$$
Y_{A}=f^{A}\left(K_{1}^{A}, K_{1}^{B}\right)=\theta_{A} K_{1}^{A \alpha_{K}}{ }_{1}^{B \phi}
$$


(57b)

$$
Y_{B}=f^{B}\left(K_{2}^{A}, K_{2}^{B}\right)={ }_{B} K_{2}^{A \alpha} K_{2}^{B \phi} .
$$

where

$$
\alpha+\phi=\psi<1 .
$$

The optimization problem of the representative household of country 1 is now given by

(58) $V\left(m_{1}^{A}+e m_{1}^{B}, K_{1}^{A}, K_{1}^{B}\right)=\max u\left(c_{1}^{A}, c_{1}^{B}\right)+\beta V\left(m_{1}^{A^{\prime}}+e^{\prime} m_{1}^{B^{\prime}}, K^{A^{\prime}},{ }_{,}{ }_{1}^{B^{\prime}}\right)$

subject to

$$
m_{1}^{A}-n_{1}^{A} \geq p^{A} c_{1}^{A}
$$

$$
m_{1}^{B}-n_{1}^{B} \geq p^{B} c_{1}^{B}
$$

$$
b_{1}^{A} \geq p^{A} K_{1}^{A},
$$

$$
b_{1}^{B} \geq p^{B} K_{1}^{B^{\prime}}
$$

$$
Y_{A}=\theta_{A} K_{1}^{A \alpha} K_{1}^{B \phi}
$$

and where

(60) $m_{1}^{A^{\prime}}+e^{\prime} m_{1}^{B^{\prime}}=\frac{\left[m_{1}^{A}-n_{1}^{A}-p^{A} c_{1}^{A}\right]}{\left(1+X^{A}\right)}+e^{\prime} \frac{\left[m_{1}^{B}-n_{1}^{B}-p^{B} c_{1}^{B}\right]}{\left(1+X^{B}\right)}$ 


$$
\begin{gathered}
-37- \\
+\frac{n_{1}^{A}}{\left(1+X^{A}\right) q_{D}^{A}}+\frac{e^{\prime} n_{1}^{B}}{\left(1+X^{B}\right) q_{D}^{B}} \\
+\left[\frac{p^{A} Y^{A}}{\left(1+X^{A}\right)}-\frac{b_{1}^{A}}{\left(1+X^{A}\right) q_{L}^{A}}-\frac{e^{\prime} b_{1}^{B}}{\left(1+X^{B}\right) q_{L}^{B}}\right] \\
+\left[\frac{b_{1}^{A}}{1+X^{A}}-\frac{p^{A} K^{A^{\prime}}}{1+X^{A}}\right]+e^{\prime}\left[\frac{b_{1}^{B}}{1+X^{B}}-\frac{p^{B} K^{B^{\prime}}}{1+X^{B}}\right] \\
+\frac{v^{A}}{\left(1+X^{A}\right)}+\frac{s^{A}}{\left(1+X^{B}\right)} .
\end{gathered}
$$

The first-order and envelope conditions for this problem are completely analogous to the ones obtained in Section 4 with the addition of the appropriate conditions for $b_{1}^{B}$ and $K_{1}^{B}$ which are given by

$$
b_{1}^{B}: \quad \frac{e^{\prime} V_{1}^{\prime}}{\left(1+X^{B}\right)}\left[\frac{1}{q_{L}^{B}}-1\right]=\lambda_{4}
$$

$$
K^{A}: \quad \beta V_{3}^{\prime}-\beta \frac{e^{\prime} V_{1}^{\prime} P^{B}}{\left(1+X^{B}\right)}=\lambda_{4} p^{B}
$$

and the envelope condition

$$
V_{3}^{\prime}=\beta V_{1}^{\prime \prime} \frac{p^{A} f_{2}^{A^{\prime}}}{\left(1+X^{A^{\prime}}\right)}
$$


where $\lambda_{4}$ is the Lagrange multiplier associated with $(59 d) . \quad(61 b, c)$ imply

$$
\beta^{2} \frac{V_{1}^{\prime \prime} p^{A^{\prime}} f_{2}^{A^{\prime}}}{\left(1+X^{B}\right)}=p^{B}\left[\frac{\beta e^{\prime} V_{1}^{\prime}}{\left(1+X^{B}\right)}+\lambda_{4}\right]
$$

\section{A Equilibrium}

The equilibrium condition in the market for good $A$ is given by

$$
c_{1}^{A}+c_{2}^{A}+K_{1}^{A^{\prime}}+K_{2}^{A^{\prime}} \equiv c^{A}+K^{A^{\prime}}=Y^{A} .
$$

The equilibrium condition in the credit market is that the total borrowing by domestic and foreign firms are equal to the funds supplied by the banking system:

$$
b_{1}^{A}+b_{2}^{A} \equiv b^{A}=\left(n^{A}+\delta^{A}\right)(1-R) .
$$

The combined domestic and foreign "credit-in-advance" constraint for the purchase of the intermediate good $A$ imply

$$
{ }_{b}^{A}+b_{2}^{A} \equiv b^{A}=p^{A}\left(K_{1}^{A^{\prime}}+K_{2}^{A^{\prime}}\right) \equiv p^{A} K^{A^{\prime}} .
$$

Then $(63)$ and (64) give:

$$
K^{A^{\prime}}=\frac{\left(n^{A}+\delta^{A}\right)(1-R)}{p^{A}}
$$

The combined domestic and foreign "cash-in-advance" constraint for the purchase of the consumption good $A$ and equilibrium in the money market is 


$$
1-n_{1}^{A}-n_{2}^{A} \equiv 1-n^{A}=p^{A}\left[c_{1}^{A}+c_{2}^{A}\right] \equiv p^{A} c^{A} .
$$

Substituting (65) and (66) into (62),

$$
p^{A}=\frac{1+\delta^{A}-R\left(n^{A}+\delta^{A}\right)}{Y^{A}}
$$

which with (65) and (62) imply

$$
\begin{aligned}
& K^{A^{\prime}}=\frac{\left(n^{A}+\delta^{A}\right)(1-R)}{1+\delta^{A}(1-R)-n^{A} R} Y^{A} \\
& c^{A}=\frac{1-n^{A}}{1+\delta^{A}(1-R)-n^{A} R} Y^{A} .
\end{aligned}
$$

Using a procedure similar to the one used in Section 4, we obtain

$$
\beta f_{1}^{A} \equiv \beta \theta_{A} \alpha K_{1}^{A \alpha-1} K_{1}^{B \phi}=\frac{1}{{ }^{A}}
$$

$$
\beta f_{2}^{A} \equiv \beta \theta_{A} \phi K_{1}^{A \alpha_{K}} K_{1}^{B \phi-1}=\frac{1}{q_{L}^{B}} \frac{e p^{B}}{p^{A}} \frac{\left(1+X^{A}\right)}{\left(1+X^{B}\right)} .
$$

Dividing (70a) by (70b) we get

$$
K_{1}^{B}=\frac{\phi}{\alpha} \frac{p^{A}}{e p^{B}} \frac{\left(1+X^{B}\right)}{\left(1+X^{A}\right)} \frac{q_{L}^{B}}{q_{L}^{A}} K_{1}^{A} .
$$

Substituting back into (70a) we obtain the demand for capital as

(72a) $K_{1}^{A}=\left(\beta \theta_{A}\right)^{1 / 1-\psi}\left(\alpha q_{L}^{A}\right)^{1-\phi / 1-\psi}\left(\phi q_{L}^{B}\right)^{\phi / 1-\psi}$ 


$$
\left\{\frac{p^{A}}{e p^{B}} \frac{\left(1+X^{B}\right)}{\left(1+X^{A}\right)}\right\}^{\phi / 1-\psi} .
$$

Similarly,

$$
\begin{gathered}
K_{1}^{B}=\left(\beta \theta_{A}\right)^{1 / 1-\psi}\left(\alpha q_{L}^{A}\right)^{\alpha / 1-\psi}\left(\phi q_{L}^{B}\right)^{1-\alpha / 1-\psi} . \\
\left\{\frac{p^{A}}{e p^{B}} \frac{\left(1+X^{B}\right)}{\left(1+X^{A}\right)}\right\}^{1-a / 1-\psi} .
\end{gathered}
$$

We can similarly solve for the equilibrium values of $K_{2}^{A}$ and $K_{2}^{B}$ :

$$
\begin{aligned}
& K_{2}^{A}=\left(\beta \theta_{B}\right)^{1 / 1-\psi}\left(\alpha q_{L}^{A}\right)^{1-\phi / 1-\psi}\left(\phi q_{L}^{B}\right)^{\phi / 1-\psi} \\
& \left\{\frac{p^{A}}{e p^{B}} \frac{\left(1+X^{B}\right)}{\left(1+X^{A}\right)}\right\}^{\phi-1 / 1-\psi} . \\
& K_{2}^{B}=\left(\beta \theta_{B}\right)^{1 / 1-\psi}\left(\alpha q_{L}^{A}\right)^{\alpha / 1-\psi}\left(\phi q_{L}^{B}\right)^{1-\alpha / 1-\psi} \\
& \left\{\frac{p^{A}}{e p^{B}} \frac{\left(1+X^{B}\right)}{\left(1+X^{A}\right)}\right\}^{-a / 1-\psi} .
\end{aligned}
$$

Notice that, unlike the previous model, the intermediate good choice and thus output depend not only on the domestic nominal interest rate but also on the foreign one. Therefore, domestic monetary injections will affect foreign levels of output, and similarly foreign monetary policies will affect domestic output. In particular, as will be shown below, monetary shocks that lead to a reduction (increase) in 
interest rates will represent a reduction in the borrowing rate for both domestic and foreign firms. Therefore the demand for capital by domestic and foreign firms will increase (fall) and this will lead to a steady state increase (decrease) in output in the home and foreign country.

To complete the solution we need to compute the equilibrium $q_{L}^{A}$ and $q_{L}^{B}$, and thus the equilibrium $n^{A}$ and $n^{B}$. Substituting (72a, b and $73 a$ ) into (68) and using the expression (25') for $q_{L}^{A}$ we get

$$
n^{A}=\alpha \beta^{2^{\left[1+\delta^{A}(1-R)\right]}\left[1+\left(\theta_{\mathrm{B}} / \theta_{\mathrm{A}}\right)^{\left.1 / 1-\psi_{\mathrm{W}}\right]}\right.} \frac{\left[1+{ }^{A}\right)+a \beta^{2} R\left[1+\left(\theta_{\mathrm{B}} / \theta_{\mathrm{A}}\right)^{1 / 1-\psi} \mathrm{W}\right]}{\left[\left(1+X^{A}\right.\right.}
$$

where $\mathrm{W}=\left\{\frac{p^{A}}{e p^{B}} \frac{\left(1+X^{B}\right)}{\left(1+X^{A}\right)}\right\}^{-1 / 1-\psi}$

Analogously

$$
{ }_{n}^{B}=\alpha \beta^{2} \frac{\left[1+\delta^{B}(1-R)\right]\left[1+\left(\theta_{A} / \theta_{B}\right)^{1 / 1-\psi} \mathrm{W}\right]}{\left[\left(1+X^{B}\right)+a \beta^{2} R\left[1+\left(\theta_{A} / \theta_{B}\right)^{1 / 1-\psi} \mathrm{W}\right]\right.} .
$$

Equations (74a) $-(74 b)$ imply that the equilibrium solution for $n^{A}$ and $n^{B}$, and therefore for the interest rates and the equilibrium capital stocks, depend on the equilibrium value of the terms of trade $\left(p^{A} / e p^{B}\right)$. Unfortunately, solving in reduced form the system for all endogenous variables is not possible given the non-linearities in the relation between the endogenous variables in the model. We are therefore forced to use simulation analysis in order to show the effects of 
monetary injections on the capital stock and the level of economic activity. The simulation results, to be shown below, confirm that, an increase in domestic monetary injections to the banking system $\left(\delta^{A}\right)$ will lead to a reduction in the borrowing rate for domestic and foreign firms, an increase in the demand for capital by domestic and foreign firms and and an increase in the steady state output in the home and foreign country. This result implies that a monetary injection will be transmitted positively to domestic and foreign output. Conversely, an increase in monetary transfers to households $X^{A}$ (that leads to an increase in the rate of growth of money) will lead to an increase in borrowing rates for domestic and foreign firms. Therefore, the demand for capital by domestic and foreign firms will fall and the steady state levels of domestic and foreign outputs will fall as well. However, we will still observe positive comovements of domestic and foreign output.

The results of the simulations are presented in figures 1 and 2. In figure 1 we show the effects on the steady state values of interest rates, capital stocks and outputs of different values of domestic monetary injections to the banking system $\left(\delta^{A}\right)$. In figure 2 we consider the steady state effects on these variables of different values of the rate of growth of the money supply $\left(X^{A}\right)$. The parameter values for the simulations in tables 1 and 2 are: $\rho=0.05, \alpha=\phi=0.15, \gamma=1, \theta_{A}=\theta_{B}=20$. In table $1, X^{A}$ is set to zero and $\delta^{A}$ is varied over a range of values. In figure $2, \delta^{A}$ is set to zero and $X^{A}$ is varied over a range. Figure 1a shews that an increase in the monetary injection to the banking sector leads to a reduction in the domestic lending rate $\left({ }_{i}^{A}\right)$ and no change in the foreign borrowing rate. Figure $1 \mathrm{~b}$ shows that this reduction in the interest rate for borrowing firms leads to an increase in the demand for 
capital by domestic and foreign firms $\left(K_{1}^{A}, K_{1}^{A}, K_{2}^{A}\right.$ and $\left.K_{2}^{B}\right)$. In turn, this increase in the capital stocks leads to an increase in the steady state level of output in the domestic and foreign economy $\left(Y_{A}\right.$ and $\left.Y_{B}\right)$, as shown in figure $1 c$.

Conversely, figure $2 a$ shows that an increase in the rate of growth of the domestic money supply leads to an increase in the domestic deposit and lending rate $\left({ }^{A}{ }_{L}^{A}\right.$ and $\left.{ }^{A} D\right)$. In turn, this increase in the borrowing rates for firms leads to an decrease in the demand for capital by domestic and foreign firms (see figure 2b). This decrease in the capital stocks implies an decrease in the steady state level of output in the domestic and foreign economy (figure $2 c$ ).

It can be added that the simulation results presented in figures 1 and 2 are robust to the choice of the parameter values: sensitivity analysis shows that in each case we considered, increases in the monetary injection to the banking system reduce borrowing interest rates and increase output while increases in the rate of growth of money increase interest rate and decrease output.

As a final consideration, we should observe that the positive comovements between domestic and foreign output levels crucially depend on the assumption that domestic and foreign capital are substitutes rather than complementary in the production function. In fact, the reduced domestic interest rates lead to an increase in the demand for domestic capital. This, in turn, increases the productivity of the foreign capital used in the production of domestic goods (if the two capital are substitutes) and leads to an increase in its demand. The reverse would happen if the two types of capital were complementary rather than substitutes. 


\section{CONCLUSIONS}

The basic result of this model is that monetary policy can have output effects even in models where price stickiness is not assumed a priori. We considered two type of monetary policy: first, an 'helicopter drop' increase in the money supply in the form of a nominal lump sum transfer from the government to the households; second, a monetary injection in the banking system that could be considered as a central bank loan to the banks (this second type of injection is assumed to be sterilized via a lump sum transfer, and thus, does not affect the rate of growth of money).

We find that temporary segmentation between assets and good markets and the asymmetric effects of monetary injections on the decisions of firms and consumers imply that monetary expansions in the form of liquidity injections in the banking system will be associated with output expansions and real exchange rate depreciations. Therefore the main implications of the Mundell-Fleming model are obtained in a model where the nonneutrality of money does not depend on stickiness of price levels which are assumed to be perfectly flexible. In this model output expansion and real exchange rate depreciation are correlated but the order of causality is reversed from the standard sticky-price model: monetary shocks lead to an output expansion that causes a worsening of domestic terms of trade (a real depreciation). We also show that while monetary injections are associated with increases in output, they do not necessarily increase welfare. Conversely, monetary transfers to the households that lead to an increase in the rate of growth of money will be associated with higher inflation and interest rates, output contractions and real exchange rate appreciations.

What can we say about the international transmission of these 
monetary shocks? In the versions of the model where only labor and domestic investment (intermediate) goods are used in the production process increases in domestic credit affect domestic output but not foreign output. However, foreign consumption and welfare are affected because of the terms of trade effects of the domestic monetary shock. In the version of the model where domestic firms use both domestic and foreign investment (intermediate) goods in the production process, domestic monetary shocks will affect in the same direction both domestic and foreign output. We therefore obtain a positive international transmission of monetary disturbances. 


\section{APPENDIX}

In order to prove that the results in the paper are not altered by the assumption ( $\left.7^{\prime}\right)$, it is sufficient to show that the negative correlation between $\delta$ and $i_{L}$ and the positive correlation between $X$ and ${ }_{i}$ hold in the more general specification given by ( $\left.7^{\prime}\right)$. Equation ( $\left.7^{\prime}\right)$ and (15a) imply:

$$
{ }_{i}^{A}=\frac{\left(1+X^{A}-\beta\right)\left(n^{A}+s \delta^{A}\right)}{\beta(1-R)\left(n^{A}+\delta^{A}\right)}
$$

Thus:

$$
{ }^{A}{ }_{L}=\frac{\beta\left(n^{A}+\delta^{A}\right)(1-R)}{\left(1+X^{A}-\beta\right)\left(n^{A}+s \delta^{A}\right)+\beta(1-R)\left(n^{A}+\delta^{A}\right)}
$$

Substituting (15a), (A.2) and (28) into (19) we obtain:

(A.3) $L_{1}=\frac{\alpha \beta^{2}\left(n^{A}+\delta^{A}\right)(1-R)(1+\gamma)}{\left[\left(1+X^{A}-\beta\right)\left(n^{A}+s \delta^{A}\right)+\beta(1-R)\left(n^{A}+\delta^{A}\right)\right]\left(1+X^{A}\right)}$

Equating (A.3) to (30) we get:

$$
n^{A}=\frac{\alpha \beta-\delta^{A}\left[\left(1+X^{A}-\beta\right) s+\beta(1-R)\right.}{1+X^{A}+\beta(\alpha-R)} .
$$

Substituting back in (A.1) we obtain the equilibrium lending rate:

$$
{ }_{i}^{A}=\frac{\left(1+X^{A}-\beta\right)\left[\alpha \beta-\delta^{A} \beta[(1-R)(1-s)-s \alpha]\right]}{\beta(1-R)\left[\alpha \beta+\delta^{A}\left[(1-s)\left(1+X^{A}-\beta\right)+\alpha \beta\right]\right]}
$$

The effects of changes in $X^{A}$ and $\delta^{A}$ on ${ }^{A}{ }_{L}^{A}$ are given by: 


$$
\begin{aligned}
& \text { (A.6) } \frac{\partial{ }_{i}^{A}}{\partial X^{A}}=\frac{\alpha \beta^{2}\left(1+\delta^{A}\right)\left[\mathrm{s} \delta^{A}[(1-R)+\alpha]+\alpha-\delta^{A}(1-R)\right]}{\left\{\beta(1-R)\left[\alpha \beta+\delta^{A}\left[(1-s)\left(1+X^{A}-\beta\right)+\alpha \beta\right]\right]\right\}^{2}}>0 \\
& \text { for } \delta^{A}<\alpha /(1-R) \text { that is a mild sufficient condition. And: }
\end{aligned}
$$

$$
\text { (A.7) } \frac{\partial i_{L}^{A}}{\partial \delta^{A}}=-\frac{(1-s) \alpha \beta\left(1+X^{A}-\beta\right)\left[1+X^{A}+\beta(\alpha-R)\right]}{\left\{\beta(1-R)\left[\alpha \beta+\delta^{A}\left[(1-s)\left(1+X^{A}-\beta\right)+\alpha \beta\right]\right\}^{2}\right.} \leq 0
$$

for $s \leq 1$. Notice that the a credit expansion leads to a reduction of the lending rate (and therefore to an output expansion) if the discount rate is below the interest rate on deposits, i.e. $s \leq 1$. This is an intuitive result since the implicit subsidization to the firm would disappear if the banks had to pay an interest rate higher or equal than the one on deposits.

\section{NOTES}

1 For example, in the numerous variations of the Mundell-Fleming model the nonneutrality of money is almost an assumption which derives straightforwardly from the hypothesis of sticky prices. An increase in money supply in these models depreciates the nominal exchange rate and given the rigidity in domestic and foreign price levels, the nominal depreciation implies a real exchange rate depreciation and thus an increase in competitiveness.

${ }^{2}$ We are assuming that domestic banks take deposits and make loans only in domestic currency. Then all the domestic monetary injection is received by domestic banks. We could alternatively assume that domestic and foreign banks take deposits and make loans in both currencies. In that case it must be assumed that the domestic monetary injection is received by both domestic and foreign banks in proportion to 
their holding of domestic monetary balances.

3 It should be observed that, while a change in $\delta^{A}$ does not affect the equilibrium exchange rate in the goods market, it still leads to a depreciation in the financial exchange rate. In this sense our model is similar to the one in Stockman and Svensson (1987) where two foreign exchange markets are sequentially open, first the one in which goods transactions are cleared and second, the one in which financial transactions occur. The reason why the exchange rate in the financial must depreciate is the following. An increase in $\delta^{A}$ leads to a reduction in domestic borrowing rates and no change in foreign borrowing rates. Since firms must be indifferent between borrowing in domestic and foreign currency, the reduction in the domestic rate must lead to an expected financial exchange rate appreciation. In order to engineer an expected appreciation the exchange rate must depreciate instantaneously. This depreciation occurs because, as foreign firms observe lower interest rates in the domestic economy, they will borrow in domestic currency and then sell the domestic currency for the foreign needed to pay their workers. These transactions depreciate the financial rate of the domestic currency. In equilibrium, a cycle of depreciation and appreciation will occur in each period because the financial rate will be depreciated relative to the goods market exchange rate. This latter exchange rate is the one used by the firms at the beginning of the next period to pay off their previous period borrowings.

\section{REFERENCES}

Aschauer, D. and J. Greenwood [1983] "A Further Exploration in the Theory of Exchange Rate Regimes," Journal of Political Economy, vol.91, no.5, October, 868-875. 
Cooley, T. F. and G.D. Hansen [1989] "The Inflation Tax in a Real Business Cycle Model," American Economic Review, vol.79, no.4, 733-748.

Fischer, S. [1979], "Capital Accumulation on the Transition Path in a Monetary Optimizing Model," Econometrica, vol.47, no.6, 1433-1439.

Fuerst, T.S. [1989], "Liquidity, Loanable Funds, and Real Activity," unpublished, University of Chicago, November.

Greenwood J. and S. Williamson [1989], "International Financial Intermediation and Aggregate Fluctuations under Alternative Exchange Rate Regimes," Journal of Monetary Economics, vol.23, no.3, May, 401-431.

Grilli, V. and N. Roubini [1989], "Financial Integration, Liquidity and Exchange Rates," NBER Working Paper No. 3088, August.

Grilli, V. and N. Roubini [1991], "Liquidity and Exchange Rates," forthcoming, Journal of International Economics.

Lucas, R.E.Jr. [1991], "Liquidity and Interest Rates," forthcoming, Journal of Economic Theory.

Sidrauski, M. [1967] "Rational Choice and Patterns of Growth in a Monetary Economy," American Economic Review, Papers and Proceedings, vol.57, May, 534-544.

Stockman, A.C. [1981], "Anticipated Inflation and the Capital Stock in a Cash-in-Advance Economy," Journal of Monetary Economics, November, 387-393.

Stockman, A. C. and L.E.O. Svensson [1987] "Capital Flows, Investment, and Exchange Rates," Journal of Monetary Economics, vol.19, 171-201.

Tobin, J. [1965], "Money and Economic Growth," Econometrica, vol.33, no.4, 671-684. 

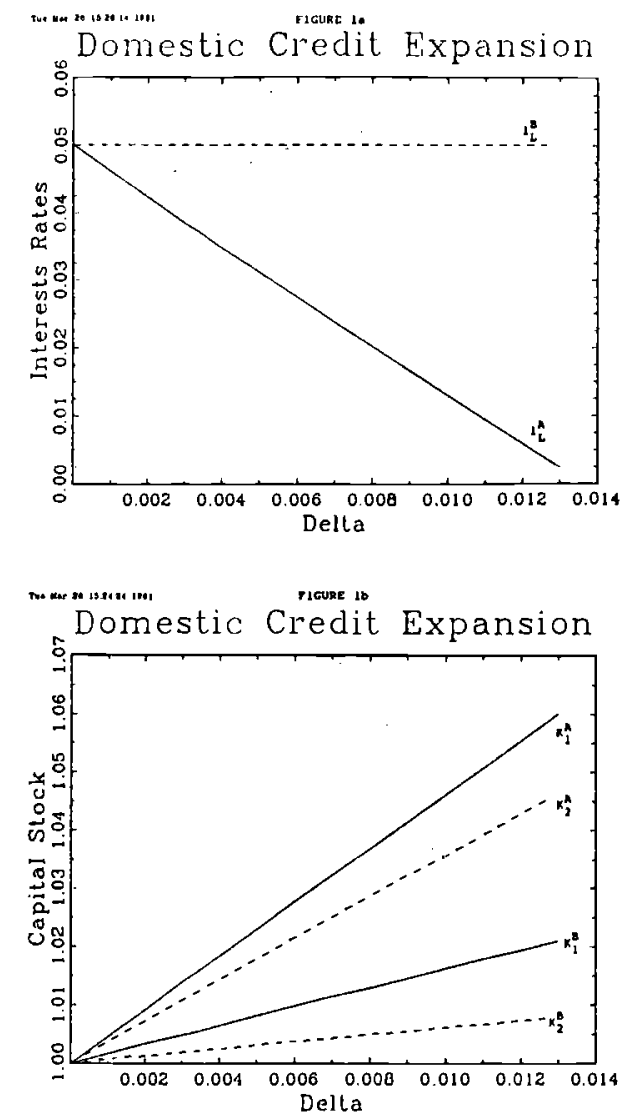

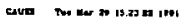

Domestic Credit Expansion

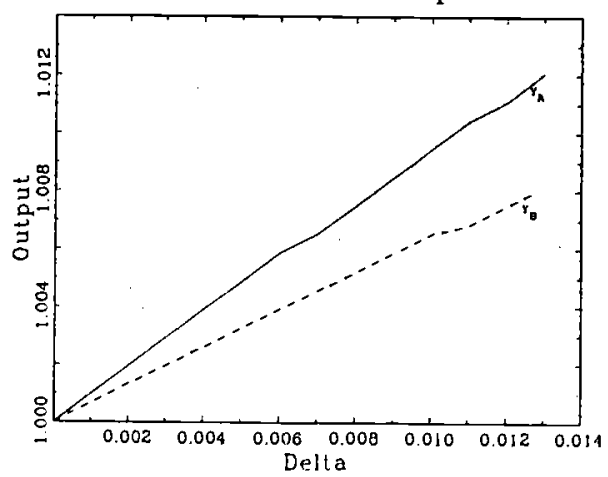


Freuhe 2.
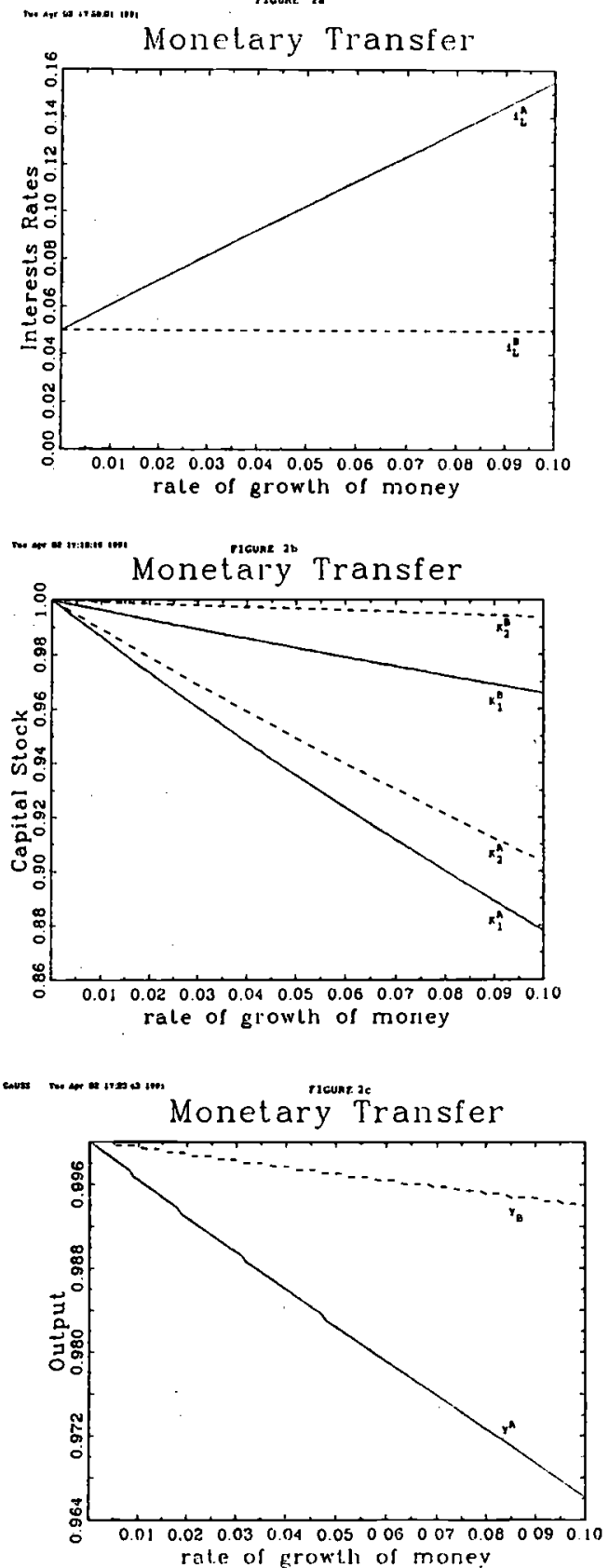